\title{
Tricuspid annular abnormalities in repaired dextro-transposition of the great arteries following Senning and Mustard procedures (Insights from the CSONGRAD Registry and MAGYAR-Path Study)
}

\author{
Attila Nemes, Gergely Rácz, Árpád Kormányos, Nándor Gyenes, Nóra Ambrus, Kálmán Havasi \\ Department of Medicine, Albert Szent-Györgyi Medical School, University of Szeged, Szeged, Hungary \\ Contributions: (I) Conception and design: A Nemes; (II) Administrative support: N Ambrus; (III) Provision of study materials or patients: A Nemes; \\ (IV) Collection and assembly of data: G Rácz, Á Kormányos; (V) Data analysis and interpretation: G Rácz, ÁKormányos, A Nemes; (VI) Manuscript \\ writing: All authors; (VII) Final approval of manuscript: All authors. \\ Correspondence to: Attila Nemes, MD, PhD, DSc, FESC. Department of Medicine, Albert Szent-Györgyi Medical School, University of Szeged, \\ H-6725 Szeged, Semmelweis street 8, P.O. Box 427, Hungary. Email: nemes.attila@med.u-szeged.hu.
}

Background: In dextro-transposition of the great arteries (dTGA), the aorta and the pulmonary artery are transposed in position, when aorta arises from the right ventricle and pulmonary artery arises from the left ventricle. The present study was designed to assess three-dimensional speckle-tracking echocardiographyderived tricuspid annular (TA) abnormalities in adult patients with dTGA late after atrial switch operations. It was also examined whether differences in TA morphology and function exist between Senning- and Mustard-procedures.

Methods: The study consisted of 14 adult dTGA patients (mean age: $29.9 \pm 8.3$ years, 6 males), who underwent Mustard-procedure $(n=7)$ at the age of $1.57 \pm 0.53$ years or Senning-procedure $(n=7)$ at the age of $1.42 \pm 0.53$ years. Their results were compared to 28 age- and gender-matched healthy subjects $(30.3 \pm 4.9$ years, 14 males).

Results: Dilated end-systolic and end-diastolic TA diameters, areas and perimeters could be detected in dTGA patients as compared to those of controls. TA functional properties calculated from TA diameter (TAFS) and area (TAFAC) data proved to be deteriorated in dTGA patients. No differences could be detected either in TA dimensions, or in TA functional properties between Senning- and Mustard-operated dTGA patients. TA plane systolic excursion (TAPSE) was reduced, which did not correlate with TAFAC and TAFS in dTGA patients.

Conclusions: In dTGA, dilated end-systolic and end-diastolic TA is accompanied with deteriorated TA functional properties regardless of which atrial switch procedure was performed. Correlations between TAPSE representing longitudinal movement of the TA and TAFAC and TAFS representing sphincterlike movement of the TA disappeared, which could partially explain accompanying tricuspid functional regurgitations.

Keywords: Tricuspid annulus; function; three-dimensional echocardiography; speckle-tracking; transposition of the great arteries

Submitted May 25, 2021. Accepted for publication Oct 12, 2021.

doi: $10.21037 / \mathrm{cdt}-21-330$

View this article at: https://dx.doi.org/10.21037/cdt-21-330 


\section{Introduction}

In dextro-transposition of the great arteries (dTGA), the aorta and the pulmonary artery are transposed in position, when aorta arises from the right ventricle (RV) and pulmonary artery arises from the left ventricle (LV). dTGA is a rare, potentially life-threatening cyanotic congenital heart defect (CHD) due to non-communicating adjacent systemic and pulmonary circuits incompatible with life (1). Its etiology is unknown with a prevalence of 4.7 per 10,000 live births (2). Several surgical procedures were historically used in clinical practice shunting blood flow into the right direction including atrial-switch operations like Senningand Mustard-procedures (3-7). In recent studies, significant volumetric and functional abnormalities of certain heart chambers could be detected in adult patients with dTGA who underwent these procedures $(8,9)$. Although dTGA is frequently associated with functional valvular regurgitation, valvular annular abnormalities related to these myocardial mechanical changes have not been investigated until now.

Due to rapid development in cardiac imaging, there is an opportunity of digital acquisition of threedimensional (3D) echocardiographic datasets using special equipment, from which $3 \mathrm{D}$ volumetric and functional analysis of cardiac chambers is allowed at the same time during 3D speckle-tracking echocardiography using dedicated software programs (10-12). Moreover, 'en-face' measurement of atrioventricular valvular annuli is also a method of choice (13). The present study was designed to assess 3DSTE-derived TA abnormalities in adult patients with dTGA late after atrial switch operations. It was also examined whether differences in TA morphology and function exist between Senning- and Mustard-procedures. We present the following article in accordance with the STROBE reporting checklist (available at https://dx.doi. org/10.21037/cdt-21-330).

\section{Methods}

\section{Patient population}

The study consisted of 14 adult dTGA patients (mean age: $29.9 \pm 8.3$ years, 6 males), who underwent Mustard procedure $(\mathrm{n}=7)$ at the age of $1.57 \pm 0.53$ years or Senning procedure $(n=7)$ at the age of $1.42 \pm 0.53$ years. Their medical history originates from the Registry of $\mathrm{C}(\mathrm{S}) \mathrm{ONGenital}$ cardiac Disease patients at the University of Szeged (CSONGRAD Registry), which summarizes clinical data of more than 3000 patients with CHD since 1961 (14). Their results were compared to 28 age- and gender-matched healthy subjects $(30.32 \pm 4.88$ years, 14 males). A subjects was considered to be healthy in the absence of any disorder, pathological state, presence of cardiovascular risk factor, drug use and if echocardiography and electrocardiography proved to be normal. A special study was organized at our department to analyse clinical usefulness of 3DSTEderived parameters in certain disorders including dTGA [Motion Analysis of the heart and Great vessels bY threedimensionAl speckle-tRacking echocardiography in Pathological cases (MAGYAR-Path) Study]. All dTGA patients and controls were in sinus rhythm and underwent complete two-dimensional (2D) Doppler echocardiography and 3DSTE. The study was approved by the Institutional human research committee of the University of Szeged (project identification code: 71/2011). Informed consent was obtained from all subjects involved. The study was conducted in accordance with the Declaration of Helsinki (as revised in 2013).

\section{Two-dimensional Doppler echocardiography}

Commercially available cardiac ultrasound device (Toshiba Artida $^{\mathrm{TM}}$, Toshiba Medical Systems, Tokyo, Japan) attached to a PST-30SBP phased-array transducer was used for evaluation of the left atrial (LA) and LV dimensions according to the available guidelines (15). Valvular abnormalities and LV diastolic function were quantified by Doppler echocardiography. TA plane systolic excursion (TAPSE) was also calculated.

\section{Three-dimensional speckle-tracking echocardiography}

3DSTE was performed according to recent practices detailed earlier (10-12). Firstly, data acquisition was made using the same Toshiba Artida ${ }^{\mathrm{TM}}$ (Toshiba Medical Systems, Tokyo, Japan) echocardiographic system, while transducer was changed to a $1-4 \mathrm{MHz}$ PST-25SX matrix phasedarray transducer (Toshiba Medical Systems, Tokyo, Japan). Using ECG-gating and breath-holding, 6 wedge-shaped subvolumes were acquired from the apical window on the chest, from which full volume 3D datasets were created by the software.

\section{DSTE-derived analysis of the tricuspid annulus}

For analysis of TA parameters, planes were optimized on long-axis views to create an 'en-face' view of the TA on 


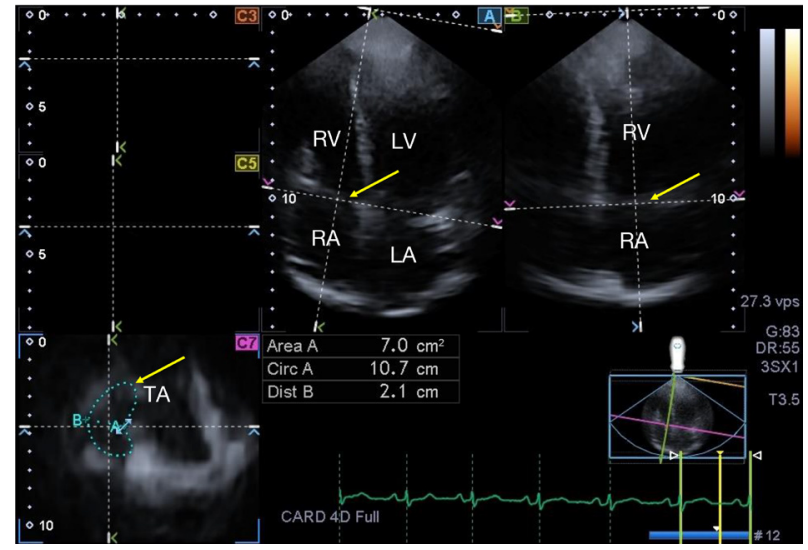

Figure 1 Three-dimensional speckle-tracking echocardiographic analysis of the tricuspid annulus using a full-volume dataset in a patient with dextro-transposition of the great arteries is presented: (A) apical four-chamber view, (B) apical two-chamber view and a cross sectional view at the level of the tricuspid annulus (C7) optimized on apical four- and two-chamber views. Yellow arrow represents the tricuspid annular plane on the long- (A,B) and short-axis (C7) images. LA, left atrium; LV, left ventricle; RA, right atrium; RV, right ventricle; TA, tricuspid annulus.

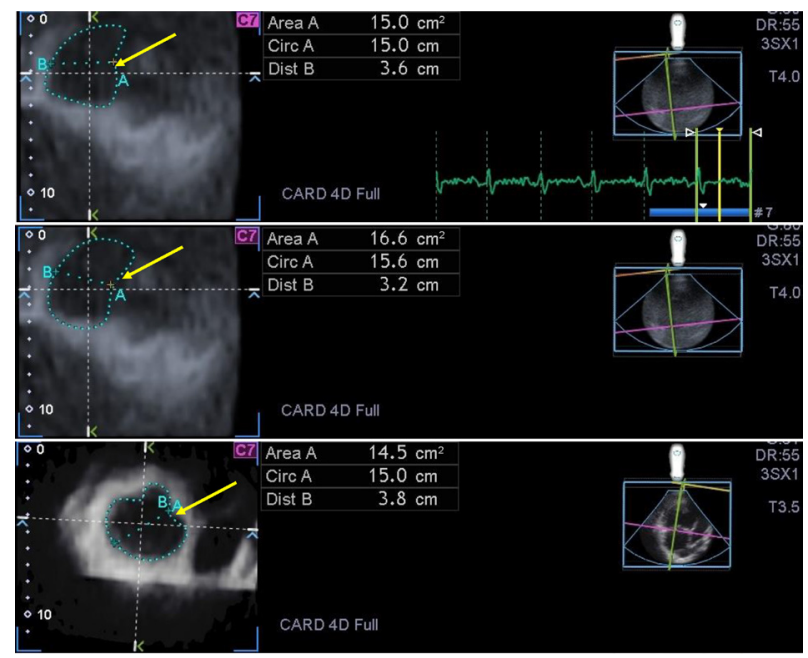

Figure 2 Some examples of deformed tricuspid annuli. Yellow arrows represent the tricuspid annular plane.

C7 short-axis view. End-diastolic (just before tricuspid valve closure) and end-systolic (just before tricuspid valve opening) measurements were performed (16) (Figures 1,2): TA morphological parameters:

* TA diameter $(\mathrm{TAD})=$ perpendicular line drawn from the peak of TA curvature to the middle of the straight TA border

* TA area (TAA), measured by planimetry

* TA perimeter (TAP), measured by planimetry

TA functional features:

* TA fractional shortening (TAFS) $=$ [end-diastolic $\mathrm{TAD}$ - end-systolic TAD]/end-diastolic TAD) $\times 100$

* TA fractional area change $($ TAFAC $)=[$ end-diastolic TAA - end-systolic TAA]/end-diastolic TAA) $\times 100$.

\section{Statistical analysis}

While continuous variables are presented as mean values \pm standard deviation, categorical variables are presented as frequencies and percentages. Student $t$-test, $\chi^{2}$ test and Fisher's exact test were used for comparisons when appropriate. $\mathrm{P}$ value less than 0.05 was considered to be statistically significant. Software package MedCalc was used during statistical analysis (MedCalc, Mariakerke, Belgium).

\section{Results}

\section{Clinical data}

Clinical and demographic data are presented in Table 1. dTGA was associated with atrial septal defect in 2 patients, ventricular septal defect was found in 3 patients and patent ductus arteriosus was present in 5 patients. The mean age at the first procedure was $1.50 \pm 0.51$ years, while the mean period between the procedure and 3DSTE proved to be $28.4 \pm 8.2$ years.

\section{Two-dimensional echocardiography}

No significant differences could be demonstrated in LA diameter $(38.4 \pm 3.2$ vs. $34.2 \pm 5.6 \mathrm{~mm}, \mathrm{P}=\mathrm{ns}), \mathrm{LV}$ enddiastolic diameter $(48.5 \pm 2.8$ vs. $46.2 \pm 4.1 \mathrm{~mm}, \mathrm{P}=\mathrm{ns})$ and volume $(108.7 \pm 19.4$ vs. $107.5 \pm 14.1 \mathrm{~mL}, \mathrm{P}=\mathrm{ns}), \mathrm{LV}$ endsystolic diameter $(32.1 \pm 2.1$ vs. $29.8 \pm 4.5 \mathrm{~mm}, \mathrm{P}=\mathrm{ns})$ and volume (37.9 \pm 7.0 vs. $37.6 \pm 9.6 \mathrm{~mL}, \mathrm{P}=\mathrm{ns})$, interventricular septum $(9.2 \pm 1.9$ vs. $102.1 \pm 3.0 \mathrm{~mm}, \mathrm{P}=\mathrm{ns}), \mathrm{LV}$ posterior wall $(8.9 \pm 1.0$ vs. $9.4 \pm 1.5 \mathrm{~mm}, \mathrm{P}=\mathrm{ns})$ and $\mathrm{LV}$ ejection fraction $(65.1 \% \pm 2.4 \%$ vs. $62.6 \% \pm 5.1 \%, \mathrm{P}=\mathrm{ns})$ between controls and dTGA patients with no differences between subgroups of Senning- and Mustard-operated patients. TAPSE proved to be $12.6 \pm 3.2 \mathrm{~mm}$ in dTGA patients, which did not differ between Senning-operated and Mustard-operated patients (13.14 \pm 3.08 vs. $12.00 \pm 3.52 \mathrm{~mm}, \mathrm{P}=\mathrm{ns})$.

Grade 1 mitral regurgitation (MR) could not be 
Table 1 Demographic data of patients with dextro-transposition of the great arteries after atrial switch and controls

\begin{tabular}{lcccc}
\hline Data & Controls $(\mathrm{n}=28)$ & All dTGA patients $(\mathrm{n}=14)$ & $\begin{array}{c}\text { Senning-operated dTGA patients } \\
(\mathrm{n}=7)\end{array}$ & $\begin{array}{c}\text { Mustard-operated dTGA } \\
\text { patients }(\mathrm{n}=7)\end{array}$ \\
\hline Age (years) & $30.2 \pm 4.88$ & $29.9 \pm 8.3$ & $22.7 \pm 3.19$ & $37.1 \pm 4.2^{*}$ \\
Male gender (\%) & $14(50)$ & $6(43)$ & $2(29)$ & $4(57)$ \\
Hypertension (\%) & $0(0)$ & $4(29)$ & $2(29)$ & $0(0)$ \\
Diabetes mellitus (\%) & $0(0)$ & $0(0)$ & $0(0)$ & $0(0)$ \\
Hypercholesterolaemia (\%) & $0(0)$ & $0(0)$ & $0(0)$ \\
\hline
\end{tabular}

dTGA, Dextro-Transposition of the Great Arteries. ${ }^{*} \mathrm{P}<0.05$ vs. Senning-operated patients.

demonstrated in any patients. Grade 2 MR [0/7 patients ( $0 \%)$ vs. $1 / 7$ patients (14\%)] did not differ between Senning-operated patients compared to Mustard-operated subjects. Higher grade MR could not be demonstrated in dTGA patients.

Grade 1, 2, 3 and 4 tricuspid regurgitation (TR) could be demonstrated in 3 (21\%), 5 (36\%), 5 (36\%) and 1 (7\%) dTGA patients with somewhat lower ratio of grade $1 \mathrm{TR}$ [2/7 patients (29\%) vs. $1 / 7$ patients $(14 \%)]$ and higher grade of 2 [2/7 patients (29\%) vs. $3 / 7$ patients (43\%)] and 3 [2/7 patients (29\%) vs. $3 / 7$ patients (43\%)] TR in Senningoperated patients compared to Mustard-operated subjects. In one Senning-operated patient, grade 4 TR was present. None of the healthy controls had significant valvular regurgitations or stenoses.

\section{Three-dimensional speckle-tracking echocardiography}

Dilated end-systolic and end-diastolic TA diameters, areas and perimeters and their BSA-indexed counterpart could be detected in dTGA patients as compared to those of controls. TA functional properties calculated from TA diameter (TAFS) and area (TAFAC) proved to be deteriorated in dTGA patients. No differences could be detected either in TA dimensions, or in TA functional properties between Senning- and Mustard-operated dTGA patients (Table 2).

\section{Correlations}

TAPSE did not show correlations with any morphological or functional TA properties in dTGA patients. Similarly, no correlations could be demonstrated between the time between the procedure and 3DSTE and any TA dimensions or parameters featuring its function.

\section{Discussion}

Due to special morphology in dTGA, blood flows from the atrium being on the morphological right side (RA) and loaded from the caval veins and the coronary sinus, to the RV via the TA and then into the aorta (not to the pulmonary artery) $(1,2,17,18)$. Until the 1990 s, atrialswitch operations were the surgical solution for dTGA. In this case, an atrial baffle is created using autologous (Senning procedure) or synthetic (Mustard procedure) tissue helping venous flow streaming to the contralateral mitral valve and LV (and pulmonary artery) (3-7). Although atrial-switch operation is considered to be an 'old-fashioned' technique, novel, more 'physiological' arterial switch procedures are available nowadays, several adult patients live in considerable good condition decades after Senning- or Mustard-procedures (3-7). Although dTGA is frequently associated with functional TR, limited information is available regarding changes in myocardial and valvular mechanics associated with these sort of procedures.

3DSTE is a relatively new non-invasive imaging modality which offers an option for evaluation of heart chambers including volumetric and functional assessment in respect with cardiac cycle using the same virtually created $3 \mathrm{D}$ cast of a certain chamber (9-13). Not only the LV, but both atria and RV could be quantitatively assessed by both systolic and diastolic volumetric, volume-based functional properties and strain parameters following data acquisition and evaluation by a special a special dedicated software. This approach offers a more realistic and complete virtual analysis. However, 3DSTE is capable of detailed assessment of atrioventricular valvular dimensions, area and perimeter in end-systole and end-diastole using the same $3 \mathrm{D}$ echocardiographic dataset allowing complete analysis 
Table 2 Comparison of three-dimensional speckle-tracking echocardiography-derived tricuspid annular morphological and functional parameters between adult patients with dextro-transposition of the great arteries after atrial switch and controls

\begin{tabular}{|c|c|c|c|c|}
\hline Data & Controls $(n=28)$ & All dTGA patients $(n=14)$ & $\begin{array}{c}\text { Senning-operated dTGA } \\
\text { patients }(n=7)\end{array}$ & $\begin{array}{c}\text { Mustard-operated dTGA } \\
\text { patients }(n=7)\end{array}$ \\
\hline \multicolumn{5}{|c|}{ Morphological parameters } \\
\hline TAD-D/BSA $\left(\mathrm{cm} / \mathrm{m}^{2}\right)$ & $1.23 \pm 0.22$ & $1.74 \pm 0.20^{*}$ & $1.75 \pm 0.20^{*}$ & $1.74 \pm 0.21^{*}$ \\
\hline TAA-D $\left(\mathrm{cm}^{2}\right)$ & $7.30 \pm 1.60$ & $13.16 \pm 2.68^{\star}$ & $13.71 \pm 3.10^{\star}$ & $12.60 \pm 2.28^{*}$ \\
\hline TAP-D (cm) & $10.39 \pm 1.65$ & $13.93 \pm 1.57^{*}$ & $14.41 \pm 1.47^{\star}$ & $13.44 \pm 1.62^{*}$ \\
\hline TAP-D/BSA $\left(\mathrm{cm} / \mathrm{m}^{2}\right)$ & $5.72 \pm 1.16$ & $7.45 \pm 1.05^{\star}$ & $7.74 \pm 1.06^{*}$ & $7.16 \pm 1.03^{\star}$ \\
\hline TAD-S (cm) & $1.85 \pm 0.29$ & $2.94 \pm 0.32^{*}$ & $2.93 \pm 0.42^{*}$ & $2.94 \pm 0.20^{\star}$ \\
\hline TAP-S (cm) & $9.00 \pm 1.21$ & $12.74 \pm 1.29^{\star}$ & $12.91 \pm 1.32^{\star}$ & $12.56 \pm 1.34^{*}$ \\
\hline TAP-S/BSA $\left(\mathrm{cm} / \mathrm{m}^{2}\right)$ & $4.97 \pm 0.95$ & $6.81 \pm 0.83^{*}$ & $6.93 \pm 0.90^{*}$ & $6.68 \pm 0.82^{*}$ \\
\hline \multicolumn{5}{|l|}{ Functional parameters } \\
\hline TAFAC (\%) & $26.05 \pm 11.74$ & $15.53 \pm 5.98^{\star}$ & $17.17 \pm 4.11^{\star}$ & $13.89 \pm 7.37^{\star}$ \\
\hline TAFS (\%) & $17.37 \pm 5.69$ & $10.06 \pm 4.69^{\star}$ & $10.62 \pm 5.20^{\star}$ & $9.51 \pm 4.45^{\star}$ \\
\hline
\end{tabular}

TAA-D, end-diastolic tricuspid annular area; TAA-S, end-systolic tricuspid annular area; TAD-D, end-diastolic tricuspid annular diameter; TAD-S, end-systolic tricuspid annular diameter; TAFAC, tricuspid annular fractional area change; TAFS, tricuspid annular fractional shortening; TAP-D, end-diastolic tricuspid annular perimeter; TAP-S, end-systolic tricuspid annular perimeter; dTGA, Dextro-Transposition of the Great Arteries. *, $\mathrm{P}<0.05$ vs. Controls.

of the pumping function of the heart (13). Functional TA properties (TAFAC and TAFS) using TA diameter or area parameters are able to characterize sphincter-like motion of the TA. Together with the simple, long used M-mode echocardiography-derived TAPSE, which represents TA longitudinal movement, complete spatial analysis of the TA could be allowed during a 3DSTE-extended routine echocardiography.

To the best of the authors' knowledge, this is the first time to demonstrate 3DSTE-derived TA abnormalities in adult patients with dTGA following atrial switch operations. Dilated end-systolic and end-diastolic TA dimensions were found to be accompanied with TA functional abnormalities regardless of which atrial switch procedure (Senning versus Mustard) was performed without differences between them. In normal circumstances, all movements of $\mathrm{TA}$ in the $3 \mathrm{D}$ space show relationships between parameters characterizing its movement in different directions (longitudinal and sphincter-like). In dTGA, correlations seem to have disappeared, which could partially explain accompanying tricuspid functional regurgitations. In earlier studies, TA abnormalities were found to be associated with atrial volumes as well, which effects could not be excluded in dTGA patients either (19).

\section{Limitation section}

The following limitations have arisen during the evaluations:

* Image quality for 3DSTE is lower than that of 2D echocardiography and 3DSTE, which could significantly affect the results.

* Due to the nature of the software used, R-wave triggered measurements were made which requires ECG-gating.

* Moreover, full 3D volume datasets are obtained 
through $6 \mathrm{RR}$ intervals, which could lead to a "stitching noise" between individual subvolumes making 3D volume suboptimal for analysis.

* 3DSTE-derived volumetric, strain and rotational parameters of cardiac chambers were not examined.

* The present study did not aim to validate 3DSTEderived volumetric and strain measurements.

* Low number of dTGA patients was examined due to the rarity of the disease. Moreover, limited number of patients were treated with atrial-switch operations.

* Most dTGA patients had classical risk factors, which could affect the results.

\section{Conclusions}

In dTGA, dilated end-systolic and end-diastolic TA is accompanied with deteriorated TA functional properties regardless of which atrial switch procedure (Senning $v s$. Mustard) was performed. Correlations between TAPSE representing longitudinal movement of the TA and TAFAC and TAFS representing sphincter-like movement of the TA disappeared, which could partially explain accompanying tricuspid valvular functional regurgitations.

\section{Acknowledgments}

Funding: None.

\section{Footnote}

Provenance and Peer Review: This article was commissioned by the Guest Editors (Yskert von Kodolitsch, Harald Kaemmerer, Koichiro Niwa) for the series "Current Management Aspects in Adult Congenital Heart Disease (ACHD): Part IV" published in Cardiovascular Diagnosis and Therapy. The article has undergone external peer review.

Reporting Checklist: The authors have completed the STROBE reporting checklist. Available at https://dx.doi. org/10.21037/cdt-21-330

Data Sharing Statement: Available at https://dx.doi. org/10.21037/cdt-21-330

Conflict of Interest: All authors have completed the ICMJE uniform disclosure form (available at https:// dx.doi.org/10.21037/cdt-21-330). The series "Current Management Aspects in Adult Congenital Heart Disease
(ACHD): Part IV" was commissioned by the editorial office without any funding or sponsorship. The authors have no other conflicts of interest to declare.

Ethical Statement: The authors are accountable for all aspects of the work in ensuring that questions related to the accuracy or integrity of any part of the work are appropriately investigated and resolved. The study was approved by the Institutional human research committee of the University of Szeged (project identification code: 71/2011). Informed consent was obtained from all subjects involved. The study was conducted in accordance with the Declaration of Helsinki (as revised in 2013).

Open Access Statement: This is an Open Access article distributed in accordance with the Creative Commons Attribution-NonCommercial-NoDerivs 4.0 International License (CC BY-NC-ND 4.0), which permits the noncommercial replication and distribution of the article with the strict proviso that no changes or edits are made and the original work is properly cited (including links to both the formal publication through the relevant DOI and the license). See: https://creativecommons.org/licenses/by-nc-nd/4.0/.

\section{References}

1. Warnes CA. Transposition of the great arteries. Circulation 2006;114:2699-709.

2. Centers for Disease Control and Prevention (CDC). Improved national prevalence estimates for 18 selected major birth defects--United States, 1999-2001. MMWR Morb Mortal Wkly Rep 2006;54:1301-5.

3. Konstantinov IE, Alexi-Meskishvili VV, Williams WG, et al. Atrial switch operation: past, present, and future. Ann Thorac Surg 2004;77:2250-8.

4. Haeffele C, Lui GK. Dextro-Transposition of the Great Arteries: Long-term Sequelae of Atrial and Arterial Switch. Cardiol Clin 2015;33:543-58, viii.

5. Gaur L, Cedars A, Diller GP, et al. Management considerations in the adult with surgically modified d-transposition of the great arteries. Heart 2021;107:1613-9.

6. Morrison ML, Grant B, McCrossan BA, et al. 32 year follow up of patients following atrial redirection surgery for transposition of the great arteries. Congenit Heart Dis 2019;14:846-53.

7. Couperus LE, Vliegen HW, Zandstra TE, et al. Longterm outcome after atrial correction for transposition of 
the great arteries. Heart 2019;105:790-6.

8. Burkhardt BEU, Kellenberger CJ, Franzoso FD, et al. Right and Left Ventricular Strain Patterns After the Atrial Switch Operation for D-Transposition of the Great Arteries-A Magnetic Resonance Feature Tracking Study. Front Cardiovasc Med 2019;6:39.

9. Nemes A, Rácz G, Kormányos Á, et al. Left Atrial Volumetric and Deformation Analysis in Adult Patients with Dextro-Transposition of the Great Arteries (Insights from the CSONGRAD Registry and MAGYAR-Path Study). J Clin Med 2020;9:463.

10. Urbano-Moral JA, Patel AR, Maron MS, et al. Threedimensional speckle-tracking echocardiography: methodological aspects and clinical potential. Echocardiography 2012;29:997-1010.

11. Ammar KA, Paterick TE, Khandheria BK, et al. Myocardial mechanics: understanding and applying threedimensional speckle tracking echocardiography in clinical practice. Echocardiography 2012;29:861-72.

12. Nemes A, Kalapos A, Domsik P, et al. Three-dimensional speckle-tracking echocardiography -- a further step in non-invasive three-dimensional cardiac imaging. Orv Hetil 2012;153:1570-7.

13. Nemes A, Kovács Z, Kormányos Á, et al. The mitral annulus in lipedema: Insights from the three-dimensional speckle-tracking echocardiographic MAGYAR-Path Study. Echocardiography 2019;36:1482-91.

14. Havasi K, Kalapos A, Berek K, et al. More than 50 years'

Cite this article as: Nemes A, Rácz G, Kormányos Á, Gyenes N, Ambrus N, Havasi K. Tricuspid annular abnormalities in repaired dextro-transposition of the great arteries following Senning and Mustard procedures (Insights from the CSONGRAD Registry and MAGYAR-Path Study). Cardiovasc Diagn Ther 2021;11(6):1269-1275. doi: 10.21037/ cdt-21-330 experience in the treatment of patients with congenital heart disease at a Hungarian university hospital. Orv Hetil 2015;156:794-800.

15. Lang RM, Badano LP, Mor-Avi V, et al. Recommendations for cardiac chamber quantification by echocardiography in adults: an update from the American Society of Echocardiography and the European Association of Cardiovascular Imaging. Eur Heart J Cardiovasc Imaging 2015;16:233-70.

16. Anwar AM, Soliman OI, Nemes A, et al. Value of assessment of tricuspid annulus: real-time threedimensional echocardiography and magnetic resonance imaging. Int J Cardiovasc Imaging 2007;23:701-5.

17. Gatzoulis MA, Webb GD, Daubeney PE. (eds.) Diagnosis and management of adult congenital heart disease. 2 nd ed. Elsevier, Saunders, Edinbourgh, 2011.

18. Engelfriet $\mathrm{P}$, Boersma E, Oechslin E, et al. The spectrum of adult congenital heart disease in Europe: morbidity and mortality in a 5 year follow-up period. The Euro Heart Survey on adult congenital heart disease. Eur Heart J 2005;26:2325-33.

19. Guta AC, Badano LP, Tomaselli M, et al. The Pathophysiological Link between Right Atrial Remodeling and Functional Tricuspid Regurgitation in Patients with Atrial Fibrillation: A Three-Dimensional Echocardiography Study. J Am Soc Echocardiogr 2021;34:585-594.e1. 